\title{
Bacterial and fungal causes of infectious keratitis among patients attending Research Institute of Ophthalmology
}

\author{
Amal Ibrahim Abouzeid ${ }^{1 *}$, Somaia Abd Ellatif Eissa², Amal E. Aboelnour ${ }^{3}$ and Alaa Mohamed Reda Awad ${ }^{2}$
}

\begin{abstract}
Background: Corneal ulcer is a potentially sight threatening ocular condition and the leading cause of monocular blindness in developing countries. Knowing the predisposing factors and etiologic microorganism can help prompt diagnosis and treatment to prevent devastating outcomes

The aim of this study was to detect the prevalence of bacteria and fungi in infectious keratitis. And to detect the antimicrobial susceptibility pattern against these causative bacterial and fungal pathogens using antibacterial and antifungal disces.

Results: Out of 50 cases (= 50 eyes), fungal growth was predominant 23/50 representing $46 \%$ with Aspergillus flavus being the most prevalent 14/23(61\%). Bacterial growth was $7 / 50$ (14\%), 4/7 was gram-positive cocci (Staphylococcus aureus and Streptococcus pneumonie) and 3/7 was pseudomonas spp. While twenty out of 50 cases (40\%) showed no growth.

Conclusion: Ocular trauma was the major cause of infectious keratitis, more in rural population. Fungal growth; mainly Aspergillus spp. was the most prevalent pathogen encountered in all cases. Voriconazole proved to be the first choice in the treatment of mould keratitis with $100 \%$ susceptibility. While alarmingly, fluconazole should no longer be used for the empirical therapy as it showed resistance to all the fungal isolates.
\end{abstract}

Keywords: Keratitis risk factors, Ocular trauma, Antifungal therapy

\section{Background}

Infectious keratitis is an ocular emergency that requires prompt and specific management to preserve ocular integrity. It is infection of the cornea by infective organisms like bacteria, fungi, viruses, or parasites (Sedhu et al. 2017). It affects both males and females across all age groups worldwide. It presents clinically with pain, photophobia, redness, infiltration, corneal edema, corneal ulceration, and anterior chamber reaction. If left untreated, it can lead to endophthalmitis and even corneal perforation and blindness (Suwal et al. 2016). Keratitis rarely occurs in the normal eye because of the

\footnotetext{
* Correspondence: dr.amalibrahim88@yahoo.com

${ }^{1}$ Medical Microbiology and Immunology Unit, Department of Microbiology and Parasitology, Research Institute of Ophthalmology, Giza 12611, Egypt Full list of author information is available at the end of the article
}

cornea's natural resistance to infection (Suwal et al. 2016). However, predisposing factors such as trauma, contact lens wear, dry eyes, ocular surface disorders, and immune suppression may alter the defense mechanism of the outer eye and permit bacteria to invade the cornea (Lin et al. 2019).

Knowing the predisposing factors and etiologic microorganism can help control and prevent this problem. Etiologic and epidemiologic pattern of keratitis varies with the patient population, geographic location and climate. Bacteria and fungi are frequently responsible for suppurative keratitis especially in the developing countries (Sedhu et al. 2017).

Microbial keratitis requires prompt diagnosis and treatment to prevent devastating outcomes. This is achieved by routine microbiological examination of

\section{Springer Open}

() The Author(s). 2020 Open Access This article is licensed under a Creative Commons Attribution 4.0 International License, which permits use, sharing, adaptation, distribution and reproduction in any medium or format, as long as you give appropriate credit to the original author(s) and the source, provide a link to the Creative Commons licence, and indicate if changes were made. The images or other third party material in this article are included in the article's Creative Commons licence, unless indicated otherwise in a credit line to the material. If material is not included in the article's Creative Commons licence and your intended use is not permitted by statutory regulation or exceeds the permitted use, you will need to obtain permission directly from the copyright holder. To view a copy of this licence, visit http://creativecommons.org/licenses/by/4.0/. 
patients with keratitis in order to analyze and compare the changing trends of the etiology and their susceptibility patterns (Ranjini et al. 2016).

The aim of this study was to detect the predisposing risk factors and the causative agents of infectious keratitis, i.e., bacteria, fungi, and to detect the antimicrobial susceptibility pattern against these causative bacterial and fungal pathogens using antibacterial and antifungal disces, since the bacterial sensitivity to various antimicrobial agents varies from place to place and in the same place from time to time. The changing spectrum of microorganisms involved in ocular infections and the emergence of acquired microbial resistance dictate the need for continuous surveillance to guide empirical therapy (Tesfaye et al. 2013).

\section{Subjects and methods}

This study was carried out on fifty patients ( $=50$ eyes), presented with symptoms of infectious keratitis to the Cornea Outpatient Clinic of Research Institute of Ophthalmology in the period from April 2017 to December 2017. The study was approved by the local ethical committee.

The demographic characteristics (age, sex, residence, occupation) and risk factors of the patients were recorded. After detailed ocular examinations, ophthalmologist collected a corneal sample after taking the patient's consent.

\section{Inclusion and exclusion criteria Inclusion criteria}

Cases diagnosed clinically as infectious keratitis before giving antibiotic therapy or $48 \mathrm{~h}$ after discontinuing local or systemic antibiotics and local or systemic antifungal. Including cases with mild or moderate or severe keratitis both males and females.

\section{Exclusion criteria}

Cases with non-infectious keratitis or children. Corneal specimens were collected from the edges of the ulcer using sterile Kimura spatula under aseptic conditions by an ophthalmologist under the magnification of a slit lamp after instillation of local anesthetic eye drops. The material obtained was directly inoculated onto blood agar, MacConkey's agar, chocolate agar, and Sabouraud's dextrose agar medium (SDA) in multiple C or linear shaped streaks. Sterile cotton swab was used to rub gently the ulcer and then directly cut into a tube of sterile brain heart infusion broth medium (BHI) that was incubated at $37^{\circ} \mathrm{C}$ for $24-48 \mathrm{~h}$ and then on the second day subculture was done on blood agar, chocolate agar, MacConkey agar, and Sabouraud's dextrose agar. For direct smear examination, other corneal scrapings were taken and carefully spread on a glass slide for gram stain and $\mathrm{KOH}+\mathrm{Calcofluor}$ white stain (Robinson et al. 2016).

Blood agar, MacConkey agar, and broth were incubated aerobically at $37{ }^{\circ} \mathrm{C}$ for $24-48 \mathrm{~h}$. Chocolate agar plates were placed into a candle jar for fastidious bacterial pathogens, which require $\mathrm{CO}_{2}$ at $37{ }^{\circ} \mathrm{C}$ for $24-48 \mathrm{~h}$. The plates were examined after 24 and $48 \mathrm{~h}$. The growth of bacteria or fungus in culture is considered significant if the growth is confluent (more than 10 colonies) on the site of inoculation on solid media, or the organism was seen in the smears, or if the same organism was grown in more than one medium. SDA plates were incubated at room temperature $\left(25^{\circ} \mathrm{C}\right)$ and observed daily for the first 7 days and on alternate days for next 14 days for observing slow growing fungi.

Bacterial growth was identified by their colony morphology, gram staining and conventional biochemical tests. Antimicrobial susceptibility testing was performed by Kirby-Bauer disc diffusion method and was interpreted using the Clinical and Laboratory Standard Institute (CLSI) breakpoints, (CLSI, 2017).

The anti-bacterial discs used were erythromycin $(10 \mu \mathrm{g})$, aminoglycosides as tobramycin $(10 \mu \mathrm{g})$, amikacin $(30 \mu \mathrm{g})$, and gentamicin $(10 \mu \mathrm{g})$, fluoroquinolones as ciprofloxacin $(5 \mu \mathrm{g})$, ofloxacin $(5 \mu \mathrm{g})$, levofloxacin $(5 \mu \mathrm{g})$, gatifloxacin $(5 \mu \mathrm{g})$, moxifloxacin $(30 \mu \mathrm{g})$, polymyxin B 300 unit, chloramphenicol $(30 \mu \mathrm{g})$, teicoplanin $(30 \mu \mathrm{g})$, trimethoprim sulphamethoxazole $(1.25 / 23.75 \mu \mathrm{g})$, and cefoxitin $(30 \mu \mathrm{g})$.

Fungal growth was grossly identified by its colony morphology, pigment production and microscopically by lacto-phenol cotton blue stain. All filamentous fungal isolates were tested for their antifungal susceptibility by disc diffusion method against voriconazole $(1 \mu \mathrm{g})$, fluconazole $(25 \mu \mathrm{g})$, itraconazole $(50 \mu \mathrm{g})$, ketoconazole $(10$ $\mu \mathrm{g})$, and amphotericin B $(20 \mu \mathrm{g})$ and interpreted according to (Sabatelli et al. 2006; Espinel-Ingroff et al. 2007 and Johnson, 2008).

\section{Statistical analysis}

Analysis of data was done using Statistical Program for Social Science version 20 (SPSS Inc., Chicago, IL, USA). Quantitative variables were described in the form of mean and standard deviation. Qualitative variables were described as number and percent. Qualitative variables were compared using chi-square $(\chi 2)$ test. $P$ value $<0.05$ is considered.

\section{Results}

Demographic characteristics of the studied population are shown in Table 1.

Ocular trauma was the most common predisposing factor observed in 15/50 of the patients. Ocular trauma with organic objects as rice paddy stalks, dust and grass were reported in 9 patients, while 6 patients received 
Table 1 Demographic characteristics of the studied population

\begin{tabular}{lll}
\hline Demographics & Indicator & No. (\%) \\
\hline Age (in years) & $<20$ & $1(2 \%)$ \\
& $21-40$ & $7(14 \%)$ \\
& $41-60$ & $29(58 \%)$ \\
Sex & $>60$ & $13(26 \%)$ \\
& Male & $27(54 \%)$ \\
Occupation & Female & $23(46 \%)$ \\
& Farmers & $15(30 \%)$ \\
& Housewives & $19(38 \%)$ \\
& Other jobs as employees and industrial & $16(32 \%)$ \\
& workers (blacksmith, mechanic, and & \\
Residence & carpenter) & $19(38 \%)$ \\
& Urban & $31(62 \%)$ \\
\hline
\end{tabular}

ocular trauma with non-organic objects as metallic foreign body

Other risk factors observed in other patients are shown in Fig. 1.

There was a statistically significant difference between ocular trauma with organic and non-organic objects in relation to sex, occupation and residence while there was no statistical significant difference regarding other predisposing factors as shown in Table 2.

$P$ value $<0.05$ is considered significant

Figure 2 shows that ocular trauma with organic objects $9 / 15$ (60\%), were more in males farmers living in rural areas. While ocular trauma with non-organic objects were more in males working in other jobs as blacksmith, mechanic, and carpenter were living in urban areas.
Culture positive cases of infectious keratitis were 30/ 50 (60\%) while the remaining 20 cases (40\%) showed no growth.

Fungal growth was the most prevalent pattern of growth among culture positive cases 23/30 (77\%) with Aspergillus spp. being the most prevalent 21/ 23(91\%) followed by Fusarium spp. 2/23 (9\%). Bacterial growth among culture positive cases was $7 / 30$ (23\%); 3/7were S. aureus, 3/7 was Pseudomonas spp. and the remaining isolate was Streptococcal pneumoniae as shown in Fig. 3.

The type of isolated pathogens of keratitis in relation to demographic characteristics among the studied populations was as follows:

Regarding sex: there was no difference between males and females regarding bacterial or fungal causes. Regarding residence: patients who lived in rural areas were more exposed to fungal infection than urban ones. Regarding occupation: farmers and housewives were more exposed to fungal infection than other occupations. There was no statistically significant difference between bacterial and fungal infection regarding demographic characteristics as shown in Table 3.

Regarding predisposing factors in relation to causative agent of infectious keratitis, ocular trauma was the most common predisposing factor with the positive culture cases 11/30 (37\%) of the patients. Also among patients with positive culture, history of corneal injury with organic object, history of diabetes mellitus, previous ocular surgery and topical steroids represented 8/30 (27\%), 7/ $30(24 \%), 7 / 30(24 \%)$, and $3 / 30(10 \%)$ of cases, respectively. While in patients with no growth, unknown predisposing factor represented $8 / 20(40 \%)$ as shown in Table 4.

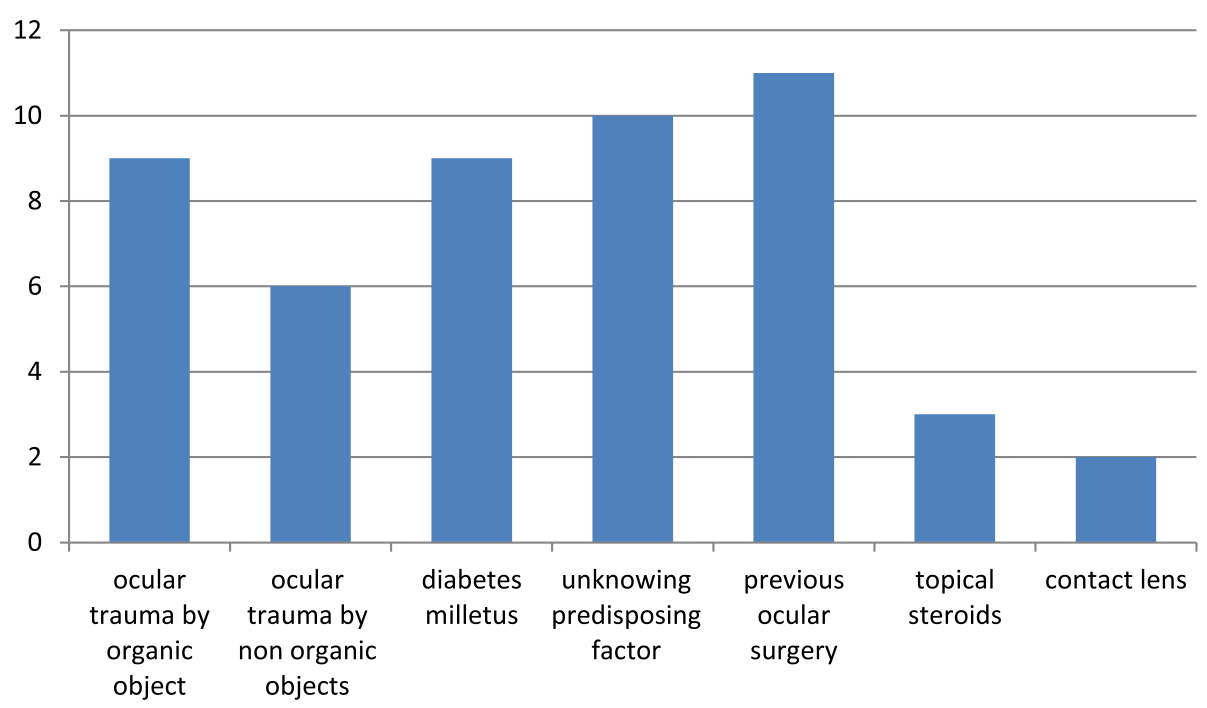

Fig. 1 Distribution of predisposing factors for keratitis among the studied population 
Table 2 Distribution of predisposing factors according to occupation, sex, and residence

\begin{tabular}{|c|c|c|c|c|c|c|c|c|c|c|}
\hline Predisposing factors & q & $\hat{0}$ & $P$ value & Urban & Rural & $P$ value & Farmer & Other jobs & Housewives & $P$ value \\
\hline Ocular trauma with non organic objects & 0 & 6 & $<0.05$ & 2 & 4 & 0.367 & 1 & 5 & 0 & $<0.05$ \\
\hline Ocular trauma with organic objects & 1 & 8 & $<0.05$ & 0 & 9 & $<0.05$ & 8 & 0 & 1 & $<0.05$ \\
\hline Previous ocular surgery & 7 & 4 & 0.365 & 6 & 5 & 0.762 & 2 & 2 & 7 & 0.103 \\
\hline Idiopathic & 4 & 6 & 0.527 & 7 & 3 & 0.157 & 1 & 4 & 5 & 0.272 \\
\hline Diabetes mellitus & 6 & 3 & 0.317 & 2 & 7 & 0.114 & 3 & 1 & 5 & 0.263 \\
\hline Contact lens & 2 & 0 & 0.157 & 2 & 0 & 0.367 & 0 & 2 & 0 & 0.135 \\
\hline Topical steroids & 3 & 0 & 0.083 & 0 & 3 & 0.223 & 0 & 2 & 1 & 0.367 \\
\hline
\end{tabular}

The antimicrobial susceptibility testing of bacterial isolates by disk diffusion method showed that out of the 7 cases of bacterial keratitis, the antibiotic susceptibility pattern of the 3 Pseudomonas isolates revealed that $(100 \%)$ were susceptible to tobramycin, amikacin and all quinolones (ciprofloxacin, ofloxacin, levofloxacin and gatifloxacin).Whereas two-thirds (66.6\%) were susceptible to both gentamicin, and polymyxin $\mathrm{B}$. while the remaining isolate showed intermediate susceptibility to both antibiotics as shown in Fig. 4 .

The antibiotic susceptibility pattern of the 3 isolates of S. aureus revealed that all isolates $(100 \%)$ were susceptible to cefoxitin, all quinolones (ciprofloxacin, ofloxacin, levofloxacin, gatifloxacin, and moxifloxacin), chloramphenicol, tobramycin and gentamicin. Teicoplanin and erythromycin $2 / 3$ (75\%) showed intermediate resistance. While one-third (33\% and $25 \%$ ) were resistant to trimethoprim sulfamethoxazole (SXT) and erythromycin, as respectively shown in Fig. 5 .

The antibiotic susceptibility pattern of the single isolate of S. pneumoniae is shown in Fig. 6.

Antifungal susceptibility pattern of the 23 fungal isolates using disk diffusion method revealed that all isolates $100 \%$ were susceptibile to voriconazole and ketoconazole, followed by itraconazole $74 \%(17 / 23)$. While $100 \%$ of isolates were resistant to fluconazole followed by amphotericin $96 \%$ (22/23). Susceptibility to itraconazole showed different results with different fungal species as shown in Fig. 7.

\section{Discussion}

In this study, the majority of patients $29 / 50$ (58\%) were between 4th and 6th decade. The incidence of infectious keratitis is higher in males $27 / 50(54 \%)$ than in females $23 / 50$ (46\%). Thirty-one out of $50(62 \%)$ of cases live in rural areas. Housewives represented 38\%, farmers 30\%, and other jobs represented $32 \%$. In similar findings, (Ravinder et al. 2016) found that infectious keratitis was more common in males (62\%) than females $(38 \%)$ more commonly observed in rural populations (65\%), with higher prevalence in agricultural workers (47.5\%) followed by industrial workers (23.75\%), housewives (12.5\%), and students (8.75\%). Sedhu et al. 2017 showed that $70 \%$ of patients with infectious keratitis lived in urban areas mainly housewives (21\%) followed by farmers $(16.9 \%)$, laborers $(13.6 \%)$, and carpenters $(12.3 \%)$

In this study, trauma was the most common predisposing factor observed in 15/50 (30\%) of infectious keratitis; ocular trauma with organic material represents 9/ $15(60 \%)$ and is more in male farmers living in rural areas. This is in agreement with (Ravinder et al. 2016) and (Choudhury et al. 2017) where ocular trauma was the most common predisposing factor with $46 \%$ and 69\%, respectively. Also according to Basak et al. 2005

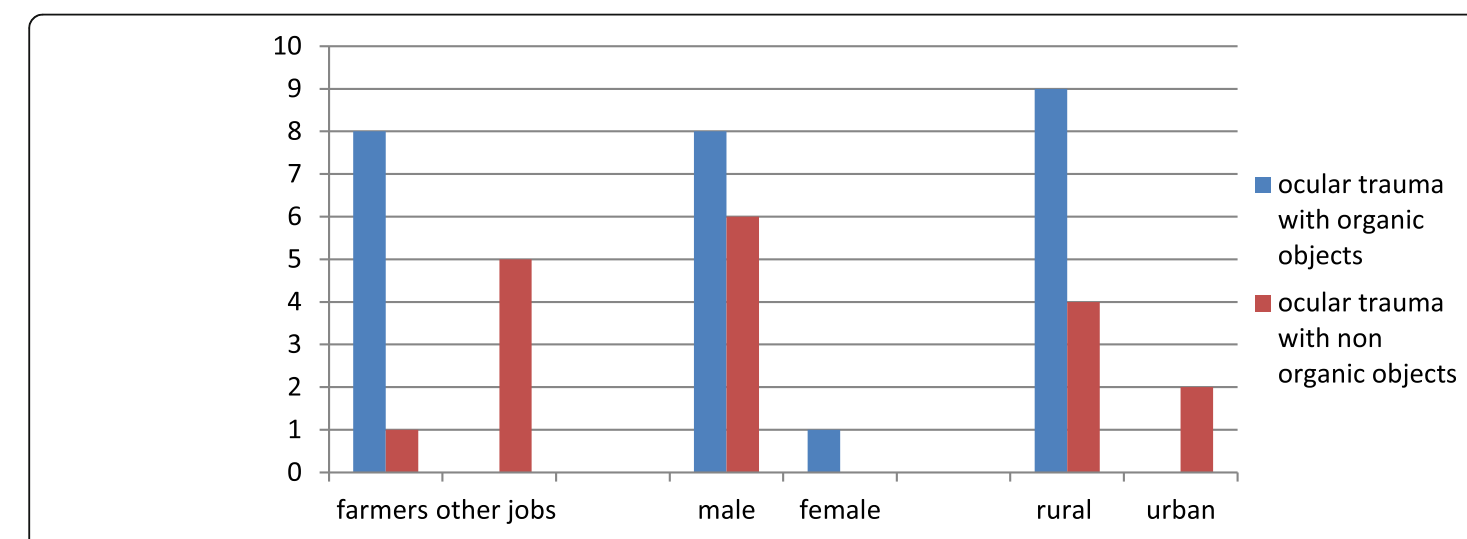

Fig. 2 Ocular trauma with organic and non-organic objects according to sex, occupation, and residence 


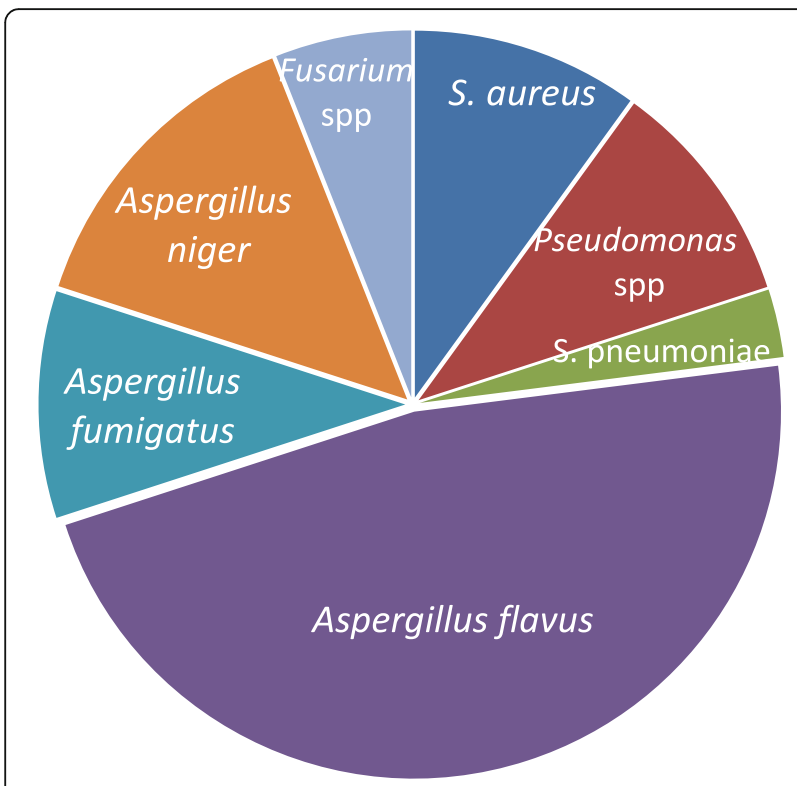

Fig. 3 Bacterial and fungal pathogens recovered from culture-positive cases

and Senthil Vadivu 2013, corneal injury with vegetable matter was the most common factor causing infectious keratitis with $59.6 \%$ and $47.817 \%$, respectively. Ravinder et al. 2016 reported that farmers were more prone for ocular trauma with organic material. El Shabrawy et al. 2013 found history of ocular trauma to be the most important predisposing factor for fungal keratitis (63.6\%). The above observations clearly show that in developing countries, agricultural workers are more prone to vegetative matter-induced ocular trauma as a major cause of infectious keratitis in rural populations more than urban populations.

While in developed countries wearing contact lense constitutes a major risk factor for infectious keratitis, according to Keay L et al. 2006, Jeng B. H. et al. 2010, and Mun et al. 2019, in our study, history of wearinf contact lens and using topical corticosteroids represented only $2 / 50(4 \%)$ and $3 / 50(6 \%)$, respectively.
In the present study, positive culture samples of infectious keratitis cases are 60\% (30/50). Similar to our results, Marasini et al. 2016, found a positive culture rate of $57.8 \%$. However, lower positive culture results were reported by Shoja and Manaviat 2004 and Amescua et al. 2012 with 40\% and 38\%, respectively. While Stefan and Nenciu 2006 and Al-Shakarchi et al. 2015 demonstrated higher results of positive corneal scraping culture samples with $86.7 \%$ and $70 \%$, respectively.

Our study showed that fungal growth is the most prevalent pattern of growth $23 / 30$ (77\%), while bacterial growth is $7 / 30(23 \%)$. This is in accordance with a study by EL Shabrawy et al. (2013) conducted in Egypt. Joshi et al. (2017) and Manikandan et al. (2019) who reported that $55 \%, 65 \%$, and $98 \%$, respectively, of culture positive cases were identified to be due to fungal causes while the remaining cases were due to bacterial causes. However, a study by Tewari et al. 2012 and Ghosh et al. 2016 reported that out of the positive isolates, $65 \%$ and $61 \%$ belonged to the bacteria, while $35 \%$ and $39 \%$ belonged to fungi, respectively.

In this study, Aspergillus spp. are being the most prevalent 21/23(91\%), followed by Fusarium spp. 2/ 23(8\%). This finding is in accordance with Al-Shakarchi 2007 and Tewari et al. 2012 who demonstrated that Aspergillus spp. was the most common isolate with 57\% and 35\% followed by Fusarium spp. with 27\% and 22\% among fungal pathogens, respectively. However, a study conducted in Egypt by EL-Shabrawy et al. 2013 revealed that the most frequent fungal pathogens were Penicillium spp. (24.2\%) followed by Aspergillus fumigatus (21.2\%) then Fusarium spp. (9\%).

The incidence of fungal keratitis is on the rise in the densely populated continents of Asia and Africa (Ravinder et al. 2016). This can be explained by the difference in climatic conditions. A study done in the National Research Centre in Egypt to detect the association between fungal keratitis and the climatic changes concluded that the climatic conditions directly affect the frequency of fungal keratitis and that the incidence of this disease will

Table 3 Distribution of demographic characteristics according to causative agent of keratitis among the studied populations

\begin{tabular}{|c|c|c|c|c|c|c|}
\hline Demographic & Indicator & total & $\begin{array}{l}\text { Bacterial keratitis } \\
N(\%)\end{array}$ & $\begin{array}{l}\text { Fungal keratitis } \\
N(\%)\end{array}$ & $\begin{array}{l}\text { No growth } \\
N(\%)\end{array}$ & $P$ value \\
\hline \multirow[t]{2}{*}{ Sex } & Male & 27 & $3(11 \%)$ & $12(44.5 \%)$ & $12(44.5 \%)$ & 0.715 \\
\hline & Female & 23 & $4(17 \%)$ & $11(48 \%)$ & $8(35 \%)$ & \\
\hline \multirow[t]{2}{*}{ Residence } & Urban & 19 & $3(16 \%)$ & $5(26 \%)$ & $11(58 \%)$ & 0.07 \\
\hline & Rural & 31 & $4(13 \%)$ & $18(58 \%)$ & $9(29 \%)$ & \\
\hline \multirow[t]{3}{*}{ Occupation } & Farmers & 15 & $1(6 \%)$ & 10(67\%) & $4(27 \%)$ & 0.124 \\
\hline & Workers & 16 & $2(12 \%)$ & $4(25 \%)$ & 10(63\%) & \\
\hline & Housewives & 19 & $4(21 \%)$ & $9(47 \%)$ & $6(32 \%)$ & \\
\hline
\end{tabular}


Table 4 Distribution of predisposing factors according to causative agents of keratitis

\begin{tabular}{|c|c|c|c|c|c|c|}
\hline \multicolumn{2}{|c|}{ Predisposing factors } & \multirow{2}{*}{$\frac{\text { Total no. }}{6}$} & \multirow{2}{*}{$\frac{\text { Bacterial Keratitis }}{2}$} & \multirow{2}{*}{$\frac{\text { Fungal keratitis }}{1}$} & \multirow{2}{*}{$\frac{\text { No growth(20) }}{3}$} & \multirow{2}{*}{$\frac{P \text { valu }}{0.606}$} \\
\hline Ocular trauma & With non organic objects & & & & & \\
\hline & With organic objects & 9 & 0 & 8 & 1 & $<0.05$ \\
\hline \multicolumn{2}{|c|}{ Diabetes mellitus } & 9 & 0 & 7 & 2 & $<0.05$ \\
\hline \multicolumn{2}{|c|}{ Previous ocular surgery } & 11 & 4 & 3 & 4 & 0.913 \\
\hline \multicolumn{2}{|l|}{ Idiopathic } & 10 & 0 & 2 & 8 & $<0.05$ \\
\hline \multicolumn{2}{|l|}{ Contact lens } & 2 & 0 & 0 & 2 & 0.135 \\
\hline \multicolumn{2}{|l|}{ Topical steroids } & 3 & 1 & 2 & 0 & 0.367 \\
\hline
\end{tabular}

$P$ value $<0.05$ is considered significant

continue to rise as long as the global warming is increasing and the greenhouse gases will continue to rise (EL Shabrawy et al. 2013). Species of Fusarium and Aspergillus are widespread in nature being important pathogens in fungal keratitis (Manikandan et al. 2019).

In the present study, the bacterial growth among positive culture cases is $7 / 30$ (23\%); $3 / 7$ were $S$. aureus, $3 / 7$ was Pseudomonas spp., and the remaining isolate was S. pneumoniae. A study conducted by AL-Yousuf, 2009 in Bahrain reported that Pseudomonas aeruginosa, Staphylococcus, and Streptococcus were the most frequent pathogens. This is near to a study by Tewari et al. 2012 and Mun et al. 2019 who reported that the most frequent bacterial isolates were $S$. aureus followed by Pseudomonas aeruginosa.

Proper diagnosis and treatment of bacterial keratitis are essential to achieve resolution of infection and minimize damage to the cornea. In our study, the antibiotic susceptibility pattern of the 3 isolates of $S$. aureus revealed (100\%) susceptibility to cefoxitin (methicillin sensitive) and all quinolones (ciprofloxacin, ofloxacin, levofloxacin, gatifloxacin, and moxifloxacin). This is in accordance with Senthil Vadivu 2013 who founded 7/9 (77\%) methicillin-sensitive S. aureus, with $77 \%$ sensitivity to ciprofloxacin and Mun et al. 2019 who reported 11/13(85\%) methicillin-sensitive $S$. aureus with higher sensitivity to levofloxacin and moxifloxacin; 95.8\% and $93.8 \%$, respectively. Treatment of $P$. aeruginosa eye infections often becomes a challenge due to the ability of this bacterium to be resistant to antibiotics via intrinsic and acquired mechanisms (Subedi et al. 2018). In the present study, the 3 Pseudomonas isolates $(100 \%)$ were susceptible to tobramycin, amikacin , ciprofloxacin, ofloxacin, levofloxacin, and gatifloxacin followed by gentamicin and polymyxin B 2/ $3(66.6 \%)$. This is similar to a study conducted by Marasini et al. 2016 where all Pseudomonas aeruginosa isolates were sensitive to gentamicin and ciprofloxacin. Mun et al. 2019 also found that all Pseudomonas species isolates were sensitive to amikacin and ciprofloxacin. While Cho and Lee, 2018 reported less than 10\% resistance in $P$. aeruginosa to ciprofloxacin and gentamicin. According to SenthilVadivu, 2013, P. aeruginosa isolates showed lower sensitivity to ciprofloxacin (66\%) and ofloxacin (83\%).

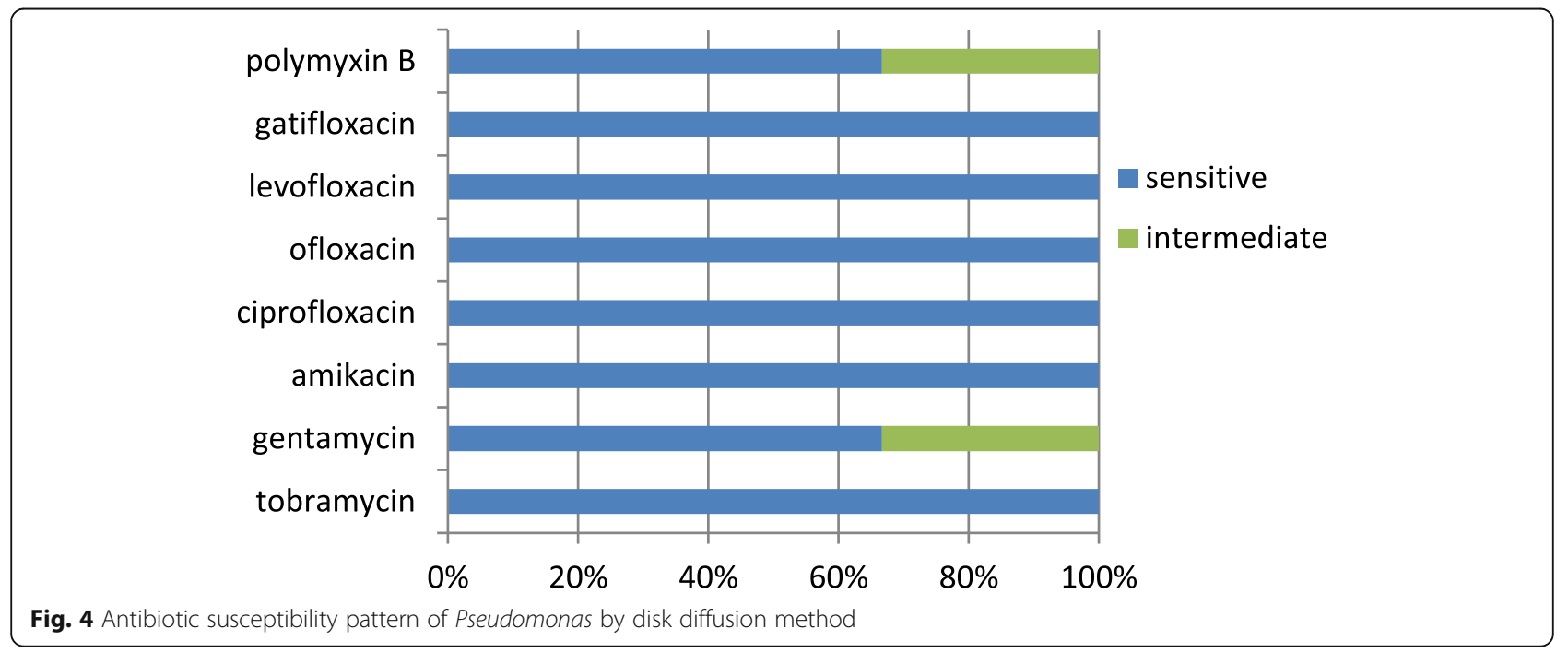




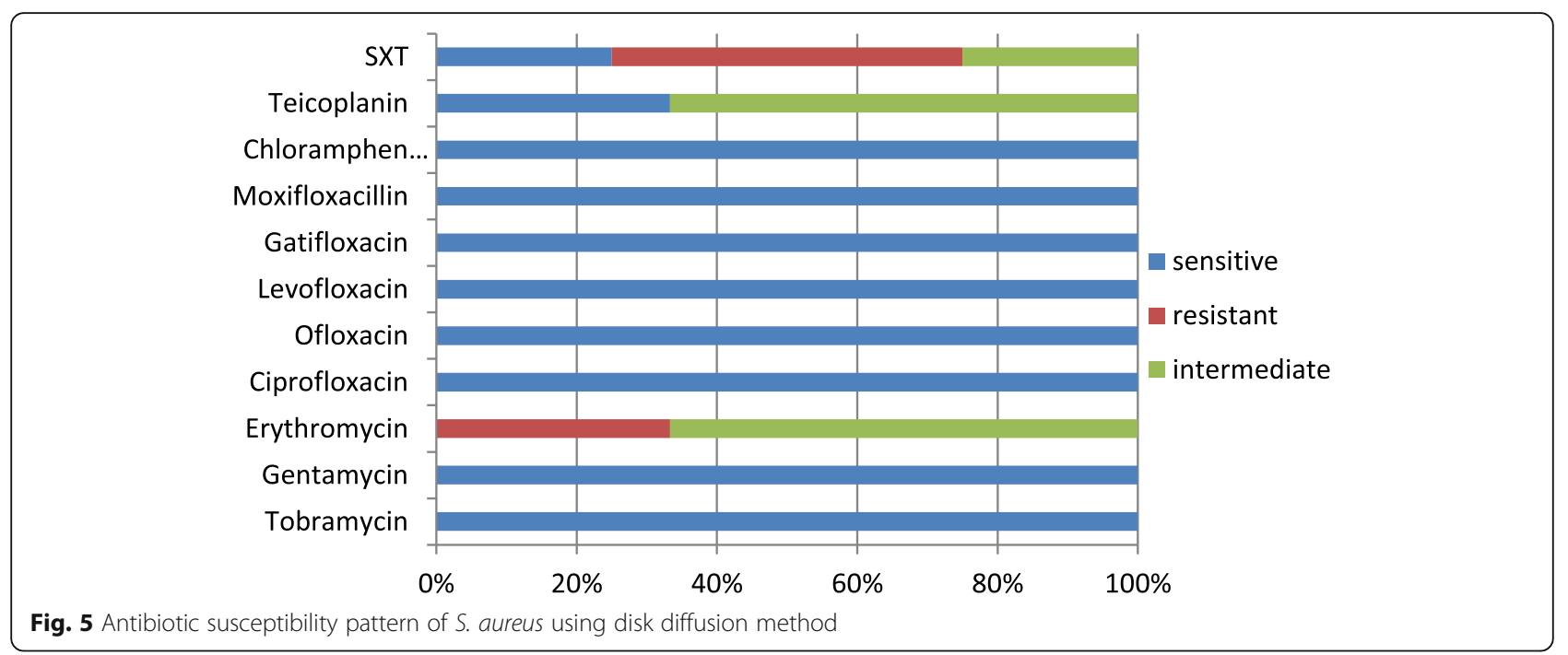

Treatment of fungal keratitis is one of the most difficult problems encountered by ophthalmologists due to poor response to the therapy as well as the limited availability of antifungal agents. Although voriconazole and other triazoles have broad-spectrum activity against causative fungal isolates, clinically no single drug was found to be effective against fungal keratitis (Manikandan et al. 2019). In this study, antifungal susceptibility pattern of the 23 fungal isolates revealed that all isolates are $100 \%$ susceptible to ketoconazole and voriconazole. In accordance with our findings, a study conducted in Upper Egypt by Gharamah et al. 2014 showed that ketoconazole at $0.5 \%$ and $1 \%$ concentrations was effective against all fungal isolates, except for three Fusarium species tested. However, Sirisha et al. 2015 reported lower percentages of sensitivity to ketoconazole for Aspergillus fumigatus (85\%), Fusarium spp. (83\%), Aspergillus flavus (73\%), and Aspergillus niger (50\%).

A study conducted by (Saha et al. 2014) showed that voriconazole had the lowest minimal inhibitory concentration (MIC) against Aspergillus spp. and Fusarium spp., followed by amphotericin B, ketoconazole, itraconazole, and that it is still the first choice in the treatment of mould keratitis.

In the present study, susceptibility to itraconazole gave different results. Both A. fumigatus and Fusarium spp. show $100 \%$ susceptibility, while $A$. flavus and $A$. niger showed intermediate susceptibility with $21 \%$ and $75 \%$, respectively. This finding is in partial agreement with Senthil vadivu 2013 where A. fumigatus and A. niger

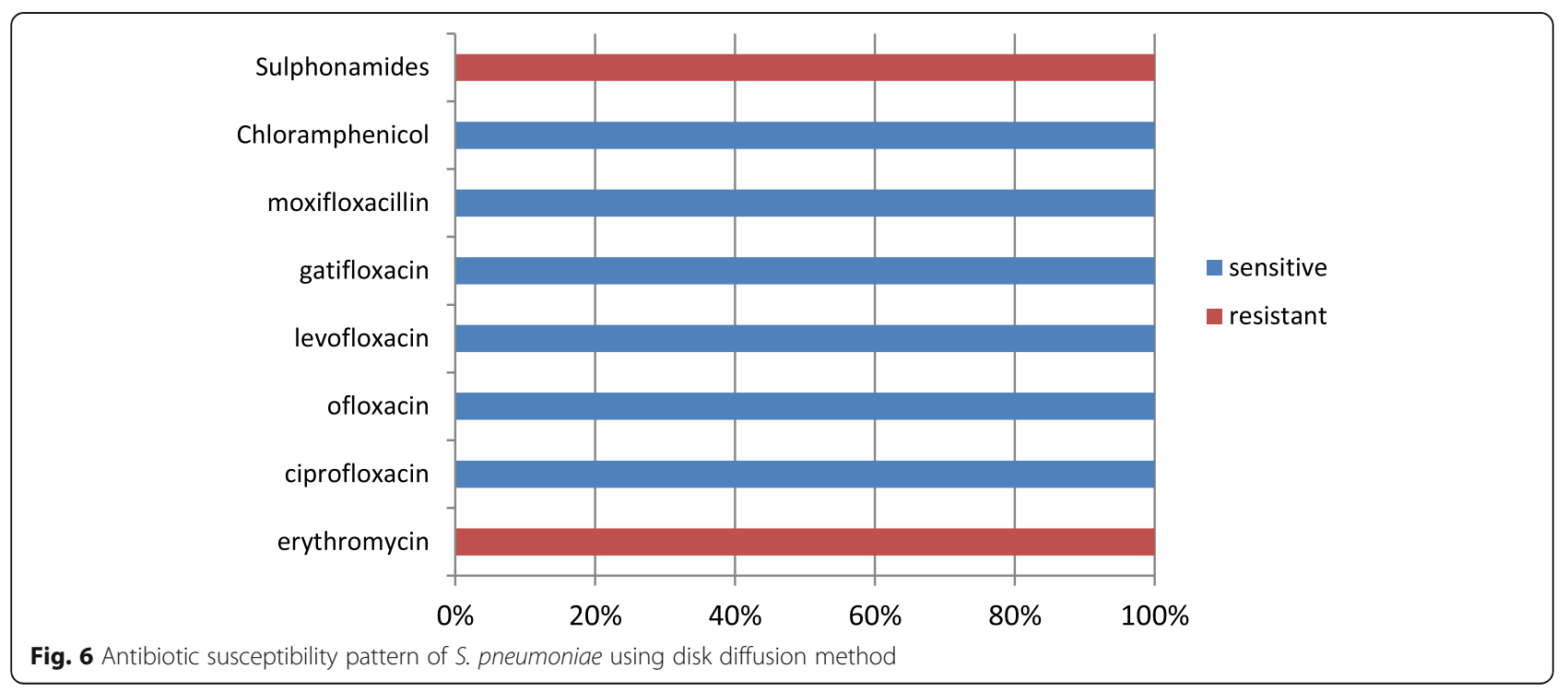




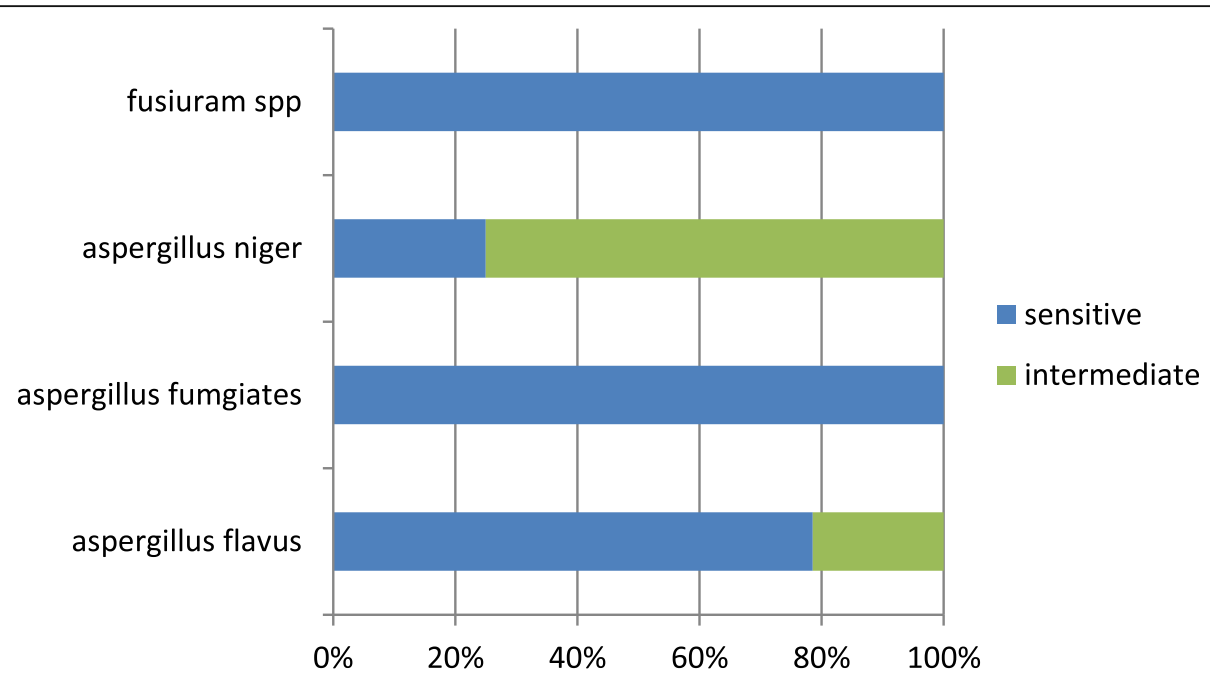

Fig. 7 Antifungal susceptibility of fungal isolates to itraconazole

showed $100 \%$ susceptibility while A. flavus and Fusarium spp. showed $78 \%$ and $83 \%$, respectively. Also a study conducted by Sirisha et al. 2015 showed that all 29 fungal isolates (Fusarium spp, A. flavus, and A.niger) were $100 \%$ susceptible to itraconazole except for A. fumigatus (85\%).

In our study, 96\% (22/23) are resistant to amphotericin B. However, Senthilvadivu 2013 reported in his study that A. fumigatus, Fusarium spp, A. flavus, and A. niger isolates were sensitive to Amphotericin B (70\%), (66\%), (64\%), and (58\%), respectively. Also, a study by Gharamah et al. (2014) showed that the (MIC) of amphotericin $\mathrm{B}$ was at $0.1 \%$ or $0.5 \%$ concentrations for most fungal species tested while there was no effect on the 3 Fusarium species. Amphotericin B was quite sensitive to genus Aspergillus and Fusarium but due to poor penetration in cornea and the requiring of high dosage, it was not used in such keratitis (Saha et al. 2014). In the present study, all isolates were resistant to fluconazole. This is in agreement with Senthil vadivu 2013, Sirisha et al. 2015, and Senthilvadivu and Stalin, 2018.

\section{Conclusion}

Ocular trauma was the major cause of infectious keratitis. It was more in the rural population. Fungal growth, mainly Aspergillus spp. was the most prevalent pathogen encountered in all cases. The incidence of fungal keratitis is on the rise due to increased global warming. Voriconazole is the first choice in the treatment of mould keratitis with $100 \%$ susceptibility. While alarmingly, fluconazole no longer can be used for the empirical therapy as it showed resistance to all fungal isolates

\section{Recommendation}

Further studies are recommended on a wider scale of population to provide more data about epidemiology and causative agents of infectious keratitis in Egypt. The practice of routine microbiological analysis and sensitivity testing for all infectious keratitis is recommended in order to have enough epidemiological information for empirical therapy.

\section{Acknowledgements}

The authors would like to thank the ophthalmology professors and all the team of cornea unit in the Research Institute of Ophthalmology (RIO) for their great help in sample preparation and sharing needed data of keratitis patients in this study.

\section{Authors' contributions}

Al had carried out the performance of lab work, the collection of data of cases, and participated in writing the manuscript. SA had made the approval of work design and research plan, supervising the steps of the work. AM supervised work steps and participated in writing the manuscript. AE participated in writing and approving the article for submission to the journal as a corresponding author. All authors read and approved the final manuscript.

\section{Funding}

Not applicable

Availability of data and materials

All data generated or analyzed during this study are included in this published article.

\section{Ethics approval and consent to participate}

The work is ethically approved by the Scientific Research Committee of the Research Institute of Ophthalmology RIO, Egypt, prior to the beginning of the study. Corneal scrapping samples used in the study were obtained after patients' consent.

\section{Consent for publication}

Not applicable.

Competing interests

The authors declare that they have no competing interests. 


\section{Author details}

'Medical Microbiology and Immunology Unit, Department of Microbiology and Parasitology, Research Institute of Ophthalmology, Giza 12611, Egypt. ${ }^{2}$ Medical Microbiology and Immunology Faculty of Medicine, Cairo University, Cairo, Egypt. ${ }^{3}$ Infection Control Unit, Microbiology and Immunology Unit, Department of Microbiology and Parasitology, (RIO), 2 El Ahram Street, Giza 12611, Egypt.

Received: 6 January 2020 Accepted: 4 May 2020

Published online: 13 May 2020

\section{References}

Al-Shakarchi Fl, Hussein MA, Al-Shaibani AB (2015) Profile of microbial keratitis at a referral center in Iraq. Journal of Al-Nahrain University 18(1):141-147

Al-Yousuf N (2009) Microbial keratitis in Kingdom of Bahrain: clinical and microbiology study. Middle East African Journal of Ophthalmology 16(1):3-7. https://doi.org/10.4103/0974-9233.48855

Amescua G, Miller D and Alfonso EC (2012). What is causing the corneal ulcer? Management strategies for unresponsive corneal ulceration. Eye (London,England); 26(2): 228-236. doi: https://doi.org/10.1038/eye.2011.316.

Basak SK, Basak S, Mohanta A, Bhowmick A (2005) Epidemiological and microbiological diagnosis of suppurative keratitis in Gangetic West Bengal, eastern India. Indian Journal of Ophthalmology 53(1):17-22

Cho CH and Lee SB. (2018). Comparison of clinical characteristics and antibiotic susceptibility between Pseudomonas aeruginosa and P. putida keratitis at a tertiary referral center: a retrospective study. BioMed Central Ophthalmology; 18(1):204.

Choudhury RB, Das DK, Das B, Bhuyan J (2017) Comparative study of bacterial profile of patients with bacterial corneal ulcer with bacterial profile of conjunctiva of controls-a prospective study. Journal of Contemporary Medical Research 4(10):2127-2130

Clinical and Laboratory Standard Insitute (2017). Performance standards for antimicrobial susceptibility testing .27th ed. CLSI supplement M100. Wayne, PA,USA,2017

EL Shabrawy RM, El Badawy NE, Harb AW (2013) The incidence of fungal keratitis in Zagazig University Hospitals, Egypt and the value of direct microscopy and PCR technique in rapid diagnosis. Journal of Microbiology and Infectious Diseases 3(4):186-191

Espinel-Ingroff A, Arthington-Skaggs B, labal N, Ellis PMA et al (2007) Multicenter Evaluation of a New Disk Agar Diffusion Method for Susceptibility Testing of Filamentous Fungi with Voriconazole, Posaconazole, Itraconazole, Amphotericin B, and Caspofungin. Journal of Clinical Microbiology 45(6): 1811-1820

Gharamah AA, Moharram AM, Ismail MA, Al-Hussaini AK (2014) Bacterial and fungal keratitis in Upper Egypt: in vitro screening of enzymes, toxins and antifungal activity. Indian journal of ophthalmology 62(2):196-203

Ghosh AK, Gupta A, Rudramurthy SM, Paul S, Hallur VK et al (2016) Fungal keratitis in North India: spectrum of agents, risk factors and treatment. Mycopathologia 181(11-12):843-850

Jeng B. H., Gritz D. C., Kumar A. B. et al.(2010) "Epidemiology of ulcerative keratitis in Northern California," Archives of Ophthalmology; 128 (8): 1022-1028.View at: Publisher Site | Google Scholar

Johnson ME (2008) Issues in antifungal susceptibility testing. Journal of Antimicrobial Chemotherapy 61(1):i13-i18

Joshi RK, Goyal RK, Kochar A (2017) A prospective study of clinical profile, epidemiology and etiological diagnosis of corneal ulcer in North-West Rajasthan. International Journal of Community Medicine and Public Health 4(12):4544-4547

Keay L, Edwards K, Naduvilath T, Taylor HR, Snibson GR et al (2006) Microbial keratitis: predisposing factors and morbidity. Ophthalmology 113:109-116

Lin A, Rhee MK, Akpek EK, Amescua G, Farid M et al (2019) Bacterial keratitis PPP. The American Academy of Ophthalmology Preferred Practice Pattern Cornea/External Disease Committee 126(1):1-55

Manikandan P, Abdel-Hadi A, RandhirBabu Singh Y, Revathi R, Anita R et al (2019) Fungal keratitis: epidemiology, rapid detection, and antifungal susceptibilities of fusarium and aspergillus isolates from corneal scrapings. BioMed Research International 2019:6395840. https://doi.org/10.1155/2019/6395840

Marasini S, Swift S, Dean SJ, Ormonde SE, Craig JP (2016) Spectrum and Sensitivity of Bacterial Keratitis Isolates in Auckland. Journal of ophthalmology 2016:3769341. https://doi.org/10.1155/2016/3769341
Mun Y, Kim KM, Oh JY (2019) Ten-year analysis of microbiological profile and antibiotic sensitivity for bacterial keratitis in Korea. PLoS ONE 14(3):e0213103

Ranjini CY, Waddepally W (2016) Microbial Profile of Corneal Ulcers in a Tertiary Care Hospital in South India. Journal of ophthalmic and vision research 11(4): 363-367

Ravinder K, Madhav MV, Archana J, Pandurang J (2016) Clinical evaluation of corneal ulcer among patients attending teaching hospital. International Journal of Contemporary Medical Research 3(4):949-952

Robinson J, Ellen J, Hadel B and Lighthizer N (2016). Collecting a corneal culture. Review of optometry Acessed online from: https://www.reviewofoptometry. com/article/collecting-a-corneal-culture

Sabatelli F, Patel R, Mann PA, Mendrick CA, Norris CC et al (2006) In Vitro activities of posaconazole, fluconazole, itraconazole, voriconazole, and amphotericin B against a large collection of clinically important molds and yeasts. Antimicrobial Agents and Chemotherapy 50(6):2009-2015

Saha S, Sengupta J, Banerjee D, Sunayana S, Khetan A et al (2014) Systemic evaluation on antifungal susceptibility of keratitis associated fungal pathogens in Eastern India. Journal of Medical Microbiology and Diagnosis 3: 134. https://doi.org/10.4172/2161-0703.1000134

Sedhu PA, Sugathan S, Pushpakaran A, Kurian C (2017). Bacterial and Fungal Profile of Infectious Keratitis: A Prospective Study. International Journal of Scientific Study; 5(8): 128-132.DOl: 10.17354/ijss/2017/533.

Senthilvadivu C (2013) Bacterial, fungal and parasitic agents in infectious keratitis patients due to trauma in a tertiary care ophthalmic hospital. Master's thesis, Madras Medical College, Chennai

Senthilvadivu C, Stalin M (2018) Antimicrobial susceptibility pattern of bacterial and fungal ocular isolates from tertiary care ophthalmic hospitals in Chennai. Journal of Evolution of Medical and Dentinsty Sciences 7(15):1868-1871

Shoja MR, Manaviat M (2004) Epidemiology and outcome of corneal ulcer in yazd shahid sadoughi hospital. Acta Medica Iranica 42(2):136-141

Sirisha T, Jayalakshmi L, Ratnakumari G, Viswamitra P (2015) Microbiological profile and their antimicrobial susceptibility in infective keratitis at Regional Eye Hospital, Visakhapatnam. Scholars Journal of Applied Medical Sciences $3(3 \mathrm{~A}): 1083-1088$

Stefan C, Nenciu A (2006) Post traumatic bacterial keratitis - a microbiological prospective clinical study. Oftalmologia. 50(3):118-122

Subedi D, Vijay AK, Willcox M (2018) Study of disinfectant resistance genes in ocular isolates of Pseudomonas aeruginosa. Antibiotics (Basel) 7(4):88. https:// doi.org/10.3390/antibiotics7040088

Suwal S, Bhandari D, Thapa P, Shrestha MK, Amatya J (2016) Microbiological profile of corneal ulcer cases diagnosed in a tertiary care ophthalmological institute in Nepal. BioMed Central ophthalmology 16(1):209. https://doi.org/ 10.1186/s12886-016-0388-9

Tesfaye T, Beyene G, Gelaw Y, Bekele S, Saravanan M (2013) Bacterial profile and antimicrobial susceptibility pattern of external ocular infections in Jimma University Specialized Hospital, Southwest Ethiopia. American Journal of Infectious Diseases and Microbiology 1(1):13-20

Tewari A, Sood N, Vegad MM, Mehta DC (2012) Epidemiological and microbiological profile of infective keratitis in Ahmedabad. Indian Journal of Ophthalmology 60(4):267-272

\section{Publisher's Note}

Springer Nature remains neutral with regard to jurisdictional claims in published maps and institutional affiliations. 